\title{
PAZ PELO DESARMAMENTO NUCLEAR: desafios contemporâneos da proibição com base no impacto humanitário
}

PEACE THROUGH NUCLEAR DISARMAMENT: contemporary challenges of the ban based on the humanitarian impact

Gustavo Oliveira Vieira ${ }^{1}$

Rafael Euclides Seidel Batista ${ }^{2}$

\begin{abstract}
RESUMO
o presente artigo tem por objetivo discutir, numa perspectiva dialética, o papel do desarmamento humanitário na construção da paz e, em específico, a ameaça da existência das armas nucleares, suas implicações perante o Direito Internacional, tomando, enquanto problema, as possibilidades e desafios de sua proibição com base em seu impacto humanitário. Para tanto, apresenta-se, inicialmente, algumas dos principais fontes jurídicas internacionais sobre a temática, bem como discute, num segundo momento, a contribuição da abordagem humanitária para a construção da paz pelo desarmamento nuclear.
\end{abstract}

Palavras-chaves: Armas nucleares; desarmamento humanitário; paz.

\begin{abstract}
This article aims to discuss, in a dialetic approach, the role of the humanitarian disarmament threat of the existence of nuclear weapons, its implications under international law and, including as the problem, the possibilities and challenges of its ban on the basis of their humanitarian impact. Therefore, presents, initially some of the main legal instruments on the subject, and in a second moment, the contribution of humanitarian approach for peacebuilding through nuclear disarmament.
\end{abstract}

Key-words: Nuclear weapons; humanitarian disarmament; peace.

\section{INTRODUÇÃO}

No início de 2014, nove estados - China, Coreia do Norte, Estados Unidos, França, Índia, Israel, Paquistão, Reino Unido e Rússia - detinham 16350 armas nucleares, das quais 4150 estariam empregadas ou em condições de uso imediato.

\footnotetext{
1 Gustavo Oliveira Vieira é doutor em Direito pela UNISINOS, professor adjunto no Curso de Relações Internacionais e Integração da Universidade Federal da Integração Latino Americana (UNILA) em Foz do Iguaçu, PR, Brasil. Autor de livros, como A Formação do Estado Democrático de Direito (UNIJUÍ, 2016) e coordenador do projeto de extensão "Desarmamento Humanitário: abordagem política" da UNILA e ativista da Dhesarme - Ação pelo Desarmamento Humanitário (dhesarme.org).

2 Rafael Euclides Seidel Batista é especialista em Direito Internacional e Econômico, UEL, Foz do Iguaçu, Brasil.
} 
Aproximadamente 1800 destas são mantidas em alerta operacional alto (tradução livre). (SIPRI, 2014 p. 187).

A questão nuclear expressa e é foco das grandes tensões políticas da contemporaneidade. Os estudos para paz, assim como os movimentos pacifistas, há muito tempo tem uma convergência importante com as campanhas pelo desarmamento e pelo controle de armas. Tal convergência tem como base o entendimento de que o armamentismo fomenta, propicia e potencializa o uso da violência, incluindo guerras, além do complicado papel político e econômico desempenhado pelas indústrias de armas - financiando campanhas políticas e gerando influência político-estratégica. Se um dos lemas que guia os estudos para paz é a paz por meios pacíficos, como diz Galtung, o desarmamento é um desdobramento necessário. Maior ainda é o respaldo dos estudos para paz e dos movimentos pacifistas quando se trata de uma arma que ameaça a própria sobrevivência do ser humano no planeta Terra, como é o caso das armas nucleares - que será objeto do presente artigo.

Diferenciadas das armas convencionais, as armas de destruição em massa (ADM), como o caso das armas nucleares, receberam tratamento jurídico e político internacional tão diversificado quanto intenso. Diversificado por se abordar o problema a partir de diversos matizes, como o desarmamento nuclear, a formação de zonas livres de armas nucleares, a cooperação e controle sobre material nuclear, a proibição e reparação ante os testes nucleares e a governança sobre a energia atômica. Para isso, variados espaços políticos internacionais e nacionais pautaram a problemática, à luz das narrativas de diferentes atores (estatais e não-estatais, nacionais e pós-nacionais) e diversas fontes de Direito Internacional também foram criadas, como tratados (bilaterais, regionais e universais), jurisprudência em casos contenciosos e opinião consultiva na Corte Internacional de Justiça, decisões de organizações internacionais, além de diversas decisões no âmbito de tratados.

Neste sentido, a proibição e o banimento de certos tipos de armas de destruição em massa, como as químicas e biológicas, estão entre as grandes conquistas do Direito Internacional contemporâneo. Entretanto, a inexistência, até um momento, de um tratado banindo armas nucleares representa uma ausência importante no Direito Internacional. 
Ainda assim, é preciso reconhecer que o Direito Internacional (Público) relativo ao desarmamento e controle de armas tem se aproximado e incorporado de modo progressivo as demandas humanitárias. Para além do desarmamento e controle de armas com enfoque estratégico, cuja prioridade diz respeito ao equilíbrio do poder, o desarmamento humanitário tem se desenvolvido como uma ramificação específica que busca responder a outra lógica, a da segurança humana, e abrindo espaço para participação maior da sociedade civil global. Uma das pautas que entrou na agenda do desarmamento humanitário é a questão nuclear, que recebeu novo capítulo com a Resolução L.41 de outubro de 2016 na $1^{\text {a }}$ Comissão da Assembleia Geral das Nações Unidas (AGNU), na qual 123 Estados aprovaram sugestão de Grupo de Trabalho da AGNU pela negociação de um novo tratado internacional sobre a proibição das armas nucleares.

0 problema que mobiliza a presente pesquisa diz respeito à seguinte pergunta: Quais os limites e perspectivas do recente enfoque humanitário à questão nuclear torna o desarmamento nuclear possível? A hipótese inicial é de que os esforços têm sido submetidos à lógica estratégico-militar, enquanto a gravidade dos problemas humanitários - do eventual uso, dos testes e riscos do armazenamento - tem sido subjugada a questões marginais, senão insignificantes, neste plano. Para tanto, o enfrentamento ao problema será conduzido em uma abordagem dialética, trazendo à tona os argumentos estratégico-militares em face dos argumentos humanitários, que inicialmente são narrados a partir das iniciativas políticas e jurídicas em torno do desarmamento nuclear.

Com isso em mente, o desenvolvimento do presente artigo será guiado para apresentar alguns dos principais marcos jurídicos internacionais relativos à questão do controle e desarmamento nuclear, escolhidos com base em sua relevância histórica para a discussão política e jurídica sobre o tema. Com isso, alguns objetivos podem ser desdobrados no seguinte problema: há perspectivas realistas para o desarmamento nuclear sob o enfoque humanitário? Sendo a resposta positiva, por quais meios? Por se tratar de um dilema que implica no enfrentamento e desvelamento de condições estruturais da geopolítica estratégico-militar, optou-se por apresentar, num primeiro momento, alguns capítulos relevantes dos tratamentos jurídico-políticos até então 
percorridos e, na segunda parte, as perspectivas e contextos da nova abordagem que se pretende construir a partir da argumentação baseada no impacto humanitário.

\section{DESARMAMENTO NUCLEAR: DILEMAS E EMBATES NACIONAIS E INTERNACIONAIS}

For peace advocates - internationalists and pacifists alike - the struggle against arms accumulation has been an essential part of the strategy for peace (CORTRIGHT, 2009, p. 93).

As mobilizações sociais e políticas pelo desarmamento e controle de armas tem trajetória longa, das proibições de certas armas na Antiguidade, há mais de dois milênios e meio, até a formação das primeiras associações civis pelo desarmamento há pouco mais de um século - a Aliança Universal das Mulheres pelo Desarmamento (Alliance universelle des femmes pour le désarmement), que depois se tornou Aliança das Mulheres pela Paz (CORTRIGHT, 2009, p. 95). Entretanto, a luta pelo desarmamento tem uma mobilização intensificada com o advento da era nuclear, após o seu primeiro teste, de 16 de julho de 1945 em Trinity, Novo México, e das tragédias perpetradas em Hiroshima e Nagasaki em 6 e 9 de agosto de 1945. Aos testes e uso bélico se seguiu uma reação intensificada na formação de atores e ações políticas pela abolição nuclear.

O impacto humanitário que abordamos aqui é o conjunto de resultados, infraestruturais, sociais e humanos, de uma ação bélica, que extrapolam os objetivos militares do ato, potencialmente violadores do Direito Internacional Humanitário, podendo perdurar por horas ou gerações. Inclui-se a morte de não combatentes, como mulheres e crianças, a destruição da infraestrutura, que afeta políticas públicas sociais, como hospitais e escolas, e fornecem acesso a realização de transportes, evacuações emergenciais, degradando e, por vezes, inviabilizando as condições de vida dos que sobreviveram. Ocorrem, também, impactos humanitários decorrentes de desastres naturais, como aqueles causados por terremotos, tsunamis, inundações, furacões, entre outros. A ação bélica é resultante da decisão humana, enquanto os desastres naturais não o são. Por consequência, a ação humanitária é o conjunto de atos que visam amenizar e restaurar os efeitos dos impactos humanitários, com práticas de auxílio direto, nos locais 
afetados, por assistência médica, logística, alimentar, habitacional, entre tantos outros campos que se fizerem necessários.

Nesse sentido, importante identificar os atores, as políticas e os processos voltados ao enfrentamento do armamento nuclear para permitir uma diferenciação entre orientações estratégico-militares e humanitárias.

\subsection{Luta pela Abolição Nuclear: atores, políticas e processos}

A era nuclear marca a plena demonstração da capacidade do homem em se autodestruir, intencionalmente. Razão pela qual os primeiros a se mobilizarem e se manifestarem contrários foram os próprios cientistas, como Leo Szilard da Univeristy of Chicago, que produziram um informe em 1944, intitulado "Prospectus on Nucleonics", para alertar sobre o problema da supremacia nuclear não gerar segurança e, também, em junho de 1945 contra o uso militar da arma nuclear sobre o Japão. Einstein, que havia encorajado o projeto Manhattan para gerar dissuasão contra Alemanha, jamais imaginou que seu uso poderia ter sido sobre o Japão, já seriamente prostrado (CORTRIGHT, 2009, p. 126-8).

Ao longo dos últimos setenta anos, diversas mobilizações foram perpetradas no âmbito da política internacional por Estados (empenhando sua diplomacia), Organizações Internacionais (criando agências e instituições dedicadas ao tema - como EURATOM e AIEA) e pela própria sociedade civil (movimentos históricos pelo desarmamento ao modo do Reaching Critical Will, formando coalizões que abarcam centenas de entidades de dezenas de países, como a ICAN - International Campaign to Abolish Nuclear Weapons, a Bang, no Brasil a Dhesarme.org, entre tantas outras).

A própria formação do Greenpeace, no ano de 1971, uma das organizações nãogovernamentais mais expressivas na luta pela proteção ambiental, tem uma conexão direta com a luta pela paz e pelo desarmamento nuclear. A iniciativa e o nome surgiram de uma mobilização de jovens estudantes universitários, ativistas e ambientalistas, contra testes nucleares subterrâneos no pacífico norte. Eles partiram num barco pesqueiro de Vancouver, Canadá, para tentar chamar a atenção da opinião pública sobre o teste nuclear que se daria na ilha de Amchitka, oeste do Alasca, e divulgar sua posição contra o mesmo, 
buscando impedir um teste nuclear. 0 grupo foi interceptado, o teste aconteceu, mas a mobilização nunca mais parou (GREENPEACE, 2016).

\subsection{Brasil no Desarmamento Nuclear}

O Brasil tem uma trajetória importante em prol do desarmamento nuclear. Os temas englobados pela questão nuclear estão presentes na política brasileira desde os anos 1930 e intensificaram-se a partir dos anos 1960, com a modernização do país. A própria Constituição da República Federativa do Brasil de 1988 estabelece, em seu artigo 21, inciso XXIII, alínea "a", que "toda atividade nuclear em território nacional somente será admitida para fins pacíficos e mediante aprovação do Congresso Nacional". Afastada a possibilidade do desenvolvimento bélico, polêmicas existem quanto ao uso para outros fins, atualmente delimitado na Estratégia de Defesa Nacional e ao volume 7 do "Plano Nacional de Energia 2030". Uma trajetória marcada, segundo anúncio da política externa, pela não-proliferação, desarmamento e direito ao uso pacífico da energia nuclear (HERZ; LAGE, 2013).

No que tange à vinculação do país aos marcos jurídicos internacionais, ressaltase o fato do Brasil aderir ao TNP e ao Tratado de Proibição Completa de Testes Nucleares (CTBT, 1998), ao Regime de Controle de Tecnologia de Mísseis (1995), ao Grupo de Supridores Nucleares, além do Tratado de Tlatelolco (1994). Segundo a pesquisadora Odete Maria de Oliveira (1996), ainda na década de 1970, no marco do governo militar, as Forças Armadas iniciaram articulações dos mecanismos exigidos para a construção da bomba.

O programa de integração nuclear do Brasil com a Argentina demonstra como esta estratégia compartilhada entre os dois ex-rivais militares criou mecanismos de confiança entre ambos, com um acordo em 1980 ("Acordo de Cooperação para o desenvolvimento e Aplicação dos Usos Pacíficos da Energia Nuclear", assinado em 17 de maio de 1980) e um tratado para oficializar o processo ("Tratado de Integração, Cooperação e Desenvolvimento entre a República Argentina e a República Federativa do Brasil", assinado em novembro de 1988), com fiscalização mútua (permitida pela "Declaração Conjunta de Fiscalização Mútua", assinada em novembro de 1990), até a 
adoção de acordos bilaterais que conduziu ao uso pacífico da energia nuclear. Segundo a autora, havia um receio de que houvesse corrida armamentista entre Brasil e Argentina. (OLIVEIRA, 1996). Hoje, o Brasil, assim como a Argentina, alinharam-se de maneira definitiva ao regime internacional de não-proliferação.

Para além da criação de atores políticos, o controle sobre armas nucleares, bem como o desarmamento nuclear, é objeto de várias fontes de direito internacional, estabelecidas tanto por meio de tratados internacionais, universais e regionais, quanto no quadro de opinião consultiva e jurisprudências da Corte Internacional de Justiça - além dos diversos mecanismos de governança e soft law lançados para esta finalidade.

\section{DIREITO INTERNACIONAL DO DESARMAMENTO NUCLEAR: CAMINHOS ESTRATÉGICO-MILITARES}

Depois da Segunda Grande Guerra, os esforços para a regulação focaram no controle sobre armas nucleares, globalmente dirigido pelo Tratado de Não-Proliferação Nuclear (TNP), assinado pelos participantes da Conferência do Comitê de Desarmamento de 1968, que conta com 190 Estados Partes (2016). De acordo com o Tratado, os denominados Estados não-nucleares se comprometeram em não desenvolver nem adquirir armas nucleares, enquanto os Estados nucleares se comprometeram em não ajudar aos demais a adquirirem tais armas. Além disso, ambos os Estados se empenharam a negociar de boa fé o desarmamento nuclear - algo ainda porvir.

Os compromissos em torno do desarmamento nuclear também cumpriram papel importante na construção da paz entre países fronteiriços e nos processos de integração regional. Europa e América Latina têm desenvolvimentos pertinentes a esse respeito. Após a II Grande Guerra, um dos primeiros passos dados para a estabilização das relações internacionais na Europa e acionados para o processo de integração regional do velho continente foi a formação da EURATOM, a Comunidade Europeia da Energia Atômica, voltada ao duplo desafio da demanda por energia e da construção de confiança no ambiente pós-guerra. No caso da América Latina, as iniciativas que se consagraram no plano jurídico-político podem ser percebidas tanto no marco bilateral - os compromissos de desarmamento nuclear entre Argentina e Brasil que se ampliaram até a formação de 
um marco de integração regional subcontinental, o MERCOSUL -, quanto na construção de uma Zona Livre de Armas Nucleares pelo Tratado de Tlatelolco (Tratado para a Proibição de Armas Nucleares na América Latina e o Caribe).

Bilateralmente, o controle de armas nucleares foi, também, objeto de vários tratados, negociados entre União Soviética e Estados Unidos. Primeiramente entre estes, o Tratado de Mísseis Anti-Balístico e os Tratados de Limitação a Armas Estratégicas I e II, reconhecidos pela sigla SALT (Strategic Arms Limitation) de 1972 e 1979, buscaram suprimir a tensão nuclear dos dois países pela limitação do emprego de armas nucleares estratégicas e mísseis de defesa.

Em 1991, estas duas potências renovaram os compromissos pelo controle de armas nucleares, promovendo um acordo para a efetiva redução de armas nucleares, o Tratado de Redução de Armas Estratégicas ou START (Strategic Arms Reduction Treaty) que foi assinado entre os dois países em 1991 e ratificado em 1994, substituindo os antigos acordos SALT I e II, sendo considerado um dos maiores e mais complexos tratados de controle de armas da história. Em 2002 os dois países assinaram, também, o Tratado sobre Reduções Estratégicas Ofensivas, conhecido pela sigla SORT (Strategic Offensive Reduction Treaty), sendo a redução das ogivas nucleares dos dois países para um número máximo de 2.200 um de seus principais pontos. Um segundo Tratado START foi assinado em 2010 e ratificado entre os dois países em 2011, sendo o mais recente e significativo acordo de redução nuclear russo-estadunidense, prevendo, entre outros, o compromisso de cada parte em limitar, no período de 7 anos, suas ogivas nucleares ao número máximo de 1.550. (SIPRI, 2016)

O problema mais premente na atualidade, relativo aos tratados internacionais sobre controle e desarmamento nuclear, é que algumas potências nucleares não estão ligadas a nenhum destes instrumentos jurídicos para controle de armas nucleares. Países como Paquistão, Índia, Israel e Coreia do Norte não participam do Tratado para não proliferação de armas nucleares - TNP. Soma-se a esta questão, o fato de que alguns destes países são politicamente instáveis enquanto outros possuem um risco potencial de conflito com seus vizinhos muito alto. Todos estes países consideram a posse de armas nucleares como uma espécie de apólice de seguro de vida política, apostando em uma 
estratégia política armamentista como forma de projeção de poder. (THÜRER, 2008, p.338)

Em meio à corrida armamentista, o conceito de zonas de paz foi criado para indicar regiões ou zonas livres de armas nucleares. Na América Latina, em 1967, elaborouse o Tratado de Tlatelolco, Tratado para a Proscrição de Armas Nucleares na América Latina e no Caribe, criando uma zona nuclearmente desmilitarizada, contando com a adesão dos 33 Estados da América Latina e Caribe. Outras áreas livres de armas nucleares foram criadas na Ásia Central, entre Cazaquistão, Quirguistão, Tadjiquistão, Turcomenistão e Uzbequistão. O Tratado de Rarotonga criou, em 1985, a Zona Livre de Armas Nucleares do Pacífico Sul; em 1971 o Oceano Índico foi declarado Zona de Paz; o Tratado da Antártica de 1959 previne, também, armas nucleares naquele território.

\subsection{Corte Internacional de Justiça: Austrália e Nova Zelândia x França (1973)}

Em 09 de maio de 1973, a Austrália e a Nova Zelândia instituíram procedimentos contra a França, perante a Corte Internacional de Justiça (CIJ), incitando a Corte que se manifestasse sobre a legalidade, perante o Direito Internacional, dos testes nucleares atmosféricos realizados pela França na região da Polinésia Francesa, no Pacífico Sul. Ressalte-se que, nesta ocasião, já existia o Tratado de Interdição Parcial de Testes Nucleares de 1963 que, em síntese, não proibia a realização de testes nucleares subterrâneos, mas sim proibia os testes atmosféricos, no espaço exterior e sob as águas. Entretanto, nesta ocasião, a França não era submetida neste documento.

Sobre a demanda interposta perante a CIJ, o governo francês declarou que considerava a Corte incompetente para julgar o caso e que não aceitaria sua jurisdição. Entretanto, no ano seguinte, em 1974, o governo francês anunciou, através de diversos pronunciamentos públicos, sua intenção em interromper os testes nucleares atmosféricos realizados na região. Diante deste fato, a Corte considerou que a França, através destes pronunciamentos, havia assumido, por meio de um ato unilateral, uma obrigação jurídica internacional e que, portanto, o objetivo da Austrália e da Nova Zelândia havia sido alcançado. 
Deste modo, a disputa chegou ao fim sem que o Tribunal se pronunciasse por uma sentença, uma vez que este entendeu que, com as declarações realizadas pelo governo francês e a interrupção dos testes nucleares, a demanda interposta pela Nova Zelândia e pela Austrália perdiam seu objeto jurídico, não havendo, portanto, nada a ser julgado ou discutido sobre a legalidade de tais testes.

Conforme aponta Antonio Augusto Cançado Trindade (2005, p. 35), a Corte Internacional de Justiça, em ambos os contenciosos sobre testes nucleares, conduziu a questão de maneira evasiva e reticente, perdendo uma oportunidade histórica de se manifestar e clarear a questão da condução de testes nucleares sob o ponto de vista do Direito Internacional, ponto central de ambas as demandas e de importância premente à própria sobrevivência humana.

Ressalte-se que a França, a partir desta ocasião, substituiu a condução de testes nucleares atmosféricos por subterrâneos, continuando a conduzir diversos testes até o início dos anos 1990. Somente em 2009, o Ministro da Defesa da França, Hervé Morin, apresentou projeto de lei sobre pagamento de indenização às vítimas (argelinas, polinésias ou francesas, civis ou militares) que possam ter-se contaminado com testes ou com o manuseio de material nuclear (SAMPAIO, 2012, p. 98).

\subsection{Corte Internacional de Justiça - Opinião Consultiva (1996)}

Por solicitação da Assembleia Geral das Nações Unidas, a Corte Internacional de Justiça emitiu um parecer consultivo de 08 de agosto de 1996 sobre "A legalidade da ameaça ou uso de armas nucleares", afirmando que nem o Direito Internacional Consuetudinário nem o Direito Internacional convencional autorizam especificamente a ameaça ou uso de armas nucleares, mas que também não possuem uma proibição completa e universal sobre a ameaça ou uso destas armas. Concluiu, ainda, que a ameaça ou uso de armas nucleares é contrário ao disposto no artigo $2^{\circ}$, item IV, que dispõe que:

todos os Membros deverão evitar em suas relações internacionais a ameaça ou o uso da força contra a integridade territorial ou a dependência política de qualquer Estado, ou qualquer outra ação incompatível com os Propósitos das Nações Unidas e da Carta das Nações Unidas (ONU, 1945) 
Ainda também apontou a opinião consultiva que a ameaça ou uso de armas nucleares também não atende aos requisitos do artigo $51^{\circ}$ da mesma Carta, que trata sobre o direito à legítima defesa individual ou coletiva.

Na parte mais controversa de seu parecer, a CIJ asseverou que a ameaça ou uso de armas nucleares seriam "geralmente contrários às regras do Direito Internacional aplicáveis aos conflitos armados, principalmente àquelas do Direito Internacional Humanitário". Entretanto, a corte entendeu que no estágio atual do Direito Internacional "não é possível concluir definitivamente se a ameaça ou uso de armas nucleares seriam lícitos ou ilícitos em uma circunstância extrema de autodefesa onde a própria existência do Estado estivesse em risco". Apesar de evasiva e permeada de ambiguidades, o parecer acabou por reconhecer que as armas nucleares causam sofrimento duradouro e indiscriminado, possuindo enorme efeito destrutivo e que os princípios do Direito Internacional Humanitário são "intransgressíveis”. (TRINDADE, 2005, p. 46)

Segundo Thürer (2008, p. 100), o problema das decisões que envolvem armas nucleares é que, geralmente, são tomadas sob o ponto de vista de teóricos ou de estrategistas. Seus argumentos giram em torno de conceitos abstratos, sendo um grande perigo tomar o fato do sofrimento humano como uma ideia abstrata. Ainda, segundo o autor, a Corte Internacional de Justiça, em seu parecer consultivo, parece ter sucumbido a estes argumentos ao considerar que o uso de armas nucleares pode ser legal para assegurar a sobrevivência de um Estado.

Na opinião consultiva de 1996, a Corte expressou o entendimento de que a ameaça ou o uso de armas nucleares é contrário aos princípios fundamentais do Direito Internacional Humanitário. Entretanto, a CIJ não alcançou uma conclusão definitiva sobre a legalidade perante o Direito Internacional sobre o uso de armas nucleares por determinado Estado em casos extremos, quando a sua própria existência estivesse ameaçada. (THÜRER, 2008, p. 337).

\subsection{Negociações para um Tratado sobre Material Físsil}

Em dezembro de 1993 a Assembleia Geral das Nações Unidas adotou a resolução 48/75 recomendando a negociação de um tratado multilateral e internacionalmente vinculativo visando o banimento da produção de material físsil para armamentos 
nucleares. Desde então, iniciaram-se as negociações com adesão da maioria dos Estados partes signatários do TNP.

O Tratado ainda não chegou à definição de um texto final que seja consenso entre os países que participam de sua construção, sendo que um dos grandes obstáculos ao avanço das negociações tem sido o tema do material físsil estocado por alguns países. Nesse sentido, alguns países são favoráveis a um tratado que proíba apenas futuras produções de material físsil, não tratando sobre os estoques já existentes, enquanto outros países acreditam que o instrumento jurídico deva, também, abordar a eliminação do material existente e estocado. (REACHING CRITICAL WILL, 2016)

\subsection{Tratado de Proibição Completa de Testes Nucleares - (CTBT)}

Desde o primeiro teste nuclear de julho de 1945, mais de 2057 explosões nucleares foram registradas ao redor do planeta em condições de testes por diversos países, sendo o último registrado recentemente em setembro de 2016, pela Coreia do Norte, criando impactos ambientais e humanitários intergeracionais e de difícil recomposição.

Em setembro de 1996, na sede da Organização das Nações Unidas, em Nova Iorque, foi aberto à assinatura o Tratado de Proibição Completa de Testes Nucleares (Comprehensive Nuclear Test Ban Treaty - CTBT), o qual prevê, em seu artigo primeiro, que "cada Estado Parte compromete-se a não realizar nenhuma explosão experimental de armas nucleares ou qualquer outra explosão nuclear e a proibir e impedir qualquer explosão nuclear em qualquer lugar sob sua jurisdição ou controle”. (SAMPAIO, 2012, p.17)

Entretanto, apesar dos altos números de assinaturas e ratificações (183 assinaturas e 166 ratificações até o momento), o Tratado ainda não entrou em vigor. Tal situação se deve às condições muito peculiares estabelecidas em seu artigo XIV, que estabelece que, para sua entrada em vigor, se faz necessária a ratificação de 44 Estados específicos, listados nominalmente, sendo que entre estes Estados, já houve, até o momento, a assinatura de 41 e a ratificação de 36 Estados. (data base: novembro de 2016). Além da proibição completa dos testes nucleares, o Tratado ainda prevê um sistema de 
monitoramento de extrema complexidade, que possa garantir a cobertura de todo o globo terrestre, com o propósito de identificar e responsabilizar possíveis testes nucleares realizados pelos Estados partes.

Contudo, apesar de ainda não ter entrado em vigor, o movimento de introdução e negociação do Tratado trouxe avanços positivos. Conforme aponta Sampaio (2012, p.27), consiste em "um indicador inquestionável que desde a adoção do CTBT, a comunidade internacional não mais reconhece a figura do "teste nuclear pacífico", sendo, todo o teste nuclear, por definição, "bélico". Ainda, segundo a mesma autora (2009, p.29) "a entrada em vigor do CTBT tornou-se, indiscutivelmente, a bandeira simbólica do movimento em prol do desarmamento e da abolição completa das armas nucleares".

\subsection{Corte Internacional de Justiça - Ilhas Marshall, 2004}

Em 24 de abril de 2004, a República das Ilhas Marshall, que foi alvo de inúmeros testes nucleares americanos entre os anos 1950 e 1970, iniciou procedimentos perante a Corte Internacional de Justiça visando responsabilizar nove "Estados-nucleares" alegando, em síntese, violações ao direito internacional em decorrência da omissão destes Estados em efetivar plenamente as obrigações de desarmamento nuclear assumidas por estes países por ocasião da assinatura do TNP e também com base em outras normas consuetudinárias do Direito Internacional.

Ocorre que dos nove países inicialmente apontados, apenas três reconheceram a competência e autoridade da CIJ para julgar o caso, sendo Reino Unido, Índia e Paquistão que apresentaram objeções preliminares à competência da Corte para julgar o caso. Neste caso, os juízes, por maioria dos votos, acolheram as argumentações preliminares destes três países entendendo que o fato de não haver uma disputa prévia e específica entre a República das Ilhas Marshall e os países apontados impedia a Corte de prosseguir com a análise do mérito e julgamento do caso por ser este um requisito prévio que deve estar presente para que a Corte possa se pronunciar em disputa contenciosa entre países. (ICJ, 2016)

\subsection{Novas Perspectivas: A resolução L.41}


Em 27 de outubro de 2016, as Nações Unidas adotaram uma resolução de fundamental importância prevendo o início das negociações em 2017 de um instrumento jurídico internacionalmente vinculante, visando a proibição das armas nucleares - que teve como um dos Estados patrocinadores a República Federativa do Brasil. Em uma reunião do primeiro comitê da Assembleia Geral das Nações Unidas, que trata de segurança e desarmamento, 123 países, a maioria das regiões da África, da América Latina, do Sudeste da Ásia e do Pacífico, votaram a favor da resolução, 38 contra (votos cooptados pelos estados nucleares e promovidos pelas articulações da OTAN, em sua grande maioria) e 16 se abstiveram.

Esta resolução, conhecida como L.41, representa um passo concreto por parte da maioria do conjunto de países integrantes das Nações Unidas no sentido de efetivamente construir um Tratado que possa proibir globalmente o uso de armas nucleares, representando uma guinada nas mais de duas décadas de paralisia nos esforços multilaterais pelo efetivo desarmamento nuclear, sendo também convergente com os incansáveis esforços empenhados paralelamente pela sociedade civil através da abordagem humanitária à questão nuclear. (ICANW, 2016; DHESARME, 2016).

Ante a todo o exposto, percebe-se que a existência e a ameaça posta pelas armas nucleares estabelecem uma série de problemas tanto humanitários quanto jurídicos ao direito internacional. Primeiro sobre a legalidade da existência e ameaça das próprias armas - abordada pelo parecer consultivo da Corte Internacional de Justiça; segundo sobre a regulação em conformidade com o Direito Internacional Humanitário - que é dificilmente viável; terceiro é relacionado à obrigação de os estados nucleares negociarem, em boa-fé, o desarmamento nuclear com base no Tratado de NãoProliferação Nuclear; quarto é sobre a legalidade e responsabilidade relativa à (im)possibilidade e as consequências dos testes nucleares - que já ocorreram mais de 2000, ainda que a Corte e um tratado já tenha sido elaborado para proibir tais testes; quinto, sobre a regulação e controle acerca da transferência de material físsil; e o sexto, que atualmente tem sido enfatizado, sobre a necessidade de se proibir considerando as catastróficas consequências humanitárias das armas nucleares.

\section{DESARMAMENTO NUCLEAR COMO DESARMAMENTO HUMANITÁRIO}


Com todas as repercussões geradas pelo equilíbrio do terror produzido pela ameaça nuclear, a discussão tradicional pautou-se por questões mais estratégicomilitares do que humanitárias. Somente com as novas abordagens fomentadas no marco do desarmamento humanitário é que a recolocação da questão nuclear, à luz dos impactos humanitários, pode ganhar novas possibilidades de enfrentamentos. Sucintamente, o desarmamento humanitário difere em conteúdo e processos do desarmamento estratégico - por focar no enfrentamento concreto dos impactos humanitários e por incluir a sociedade civil em suas discussões, com maior transparência nos processos de negociação e de implementação (SILVA, 2014).

Os novos processos e conteúdos assentados no marco do desarmamento humanitário partem da premissa de que o problema do armamentismo não pode ficar restrito aos atores militares e governamentais (diplomacia estatal), mas é uma pauta sobre a qual toda sociedade deve e/ou pode expressar seu entendimento e posicionamento. São exemplos reiterados de desarmamento humanitário a erradicação de minas terrestres (VIEIRA, 2006) e a erradicação de munições cluster (VIEIRA \& SITO, 2010).

Em que pese a não utilização de armas nucleares em conflitos armados nos últimos 70 anos, não há garantias de que não serão usadas no futuro. Além da possibilidade de uso, há de se ter em conta também o risco da posse ou manutenção destas armas, uma vez que falhas no funcionamento, incidentes, alarmes falsos e informações mal interpretadas quase levaram à detonação intencional ou acidental de armas nucleares em diversas ocasiões desde 1945. (BORRIE e CAUGHLEY, 2013, p. ix)

Atualmente, somam-se a estes cenários as novas modalidades de guerra e os novos desafios da segurança internacional com os novos atores armados não estatais. 0 diretor da Agência Internacional de Energia Atômica (AIEA) afirmou que o risco do "terrorismo nuclear" é uma possibilidade real, exortando os países a reforçar sua segurança quanto ao material nuclear. Somente a proibição e a eliminação de armas nucleares poderiam efetivamente prevenir as consequências humanitárias graves que elas implicam. 
Recentemente, a perspectiva humanitária tem adquirido atenção renovada no cenário político internacional, com declarações externando a preocupação com os riscos contínuos gerados pela opção pela manutenção deste tipo de armamento. Essa preocupação aparece no pronunciamento de alguns líderes políticos representantes de estados e da sociedade civil global, incluindo documentos multilaterais resultantes de conferências internacionais sobre o tema a seguir comentados. (CAUGHLEY, 2013, p.19).

Importante esclarecer que a perspectiva humanitária sobre as armas nucleares não se limita apenas às normas e princípios do Direito Internacional Humanitário, mas vai além e envolve, também, aspectos políticos e ético-morais acerca de suas consequências.

Esta perspectiva ganhou novo impulso a partir de 28 de maio de 2010, durante a elaboração do documento final da Conferência de Revisão do TNP, ocasião em que os 189 Estados partes adotaram o seguinte texto referente às conclusões e às recomendações do documento final:

A Conferência expressa sua profunda preocupação com as consequências humanitárias catastróficas do uso de qualquer arma nuclear e reafirma a necessidade de todos os Estados, a qualquer tempo, em respeitar as normas aplicáveis do Direito Internacional, incluindo o Direito Internacional Humanitário (tradução livre). (CAUGHLEY, 2013, p.15)

Ressalta-se que a inserção deste texto foi adotada sem apresentação de reservas por nenhum dos 190 Estados Partes. Embora esteja aquém de se efetivamente afirmar que as armas nucleares violam o Direito Internacional Humanitário, implicou em um avanço no entendimento da importância da perspectiva humanitária sobre a questão nuclear (CAUGHLEY, 2013, p.15).

Em novembro de 2011, o Conselho de Delegados do Comitê Internacional da Cruz Vermelha (CICV) e do Movimento do Crescente Vermelho, através de uma resolução, alertaram sobre o "incalculável sofrimento humano que poderia ser causado como resultado da detonação de armas nucleares". Os especialistas destas organizações apontaram com grande preocupação o fato de que não há hoje disponível qualquer meio de resposta internacional efetiva para assistir as vítimas na hipótese de uma explosão causada por arma nuclear (RITCHIE, 2013, p. 65), reforçando a mensagem de que a pauta é humanitária, além de estratégica. 
Além das míopes compreensões de que a questão se limitaria a assuntos estratégicos, o Conselho de Delegados do CICV também apontou que qualquer explosão nuclear hoje, ainda que em pequena escala, seria muito mais devastadora do que aquelas já realizadas em Hiroshima e Nagasaki, tendo em vista o expressivo aumento do potencial tecnológico de destruição das armas nucleares modernas e a grande concentração demográfica populacional presente no século XXI.

No mesmo sentido, em 2013, foi realizada a primeira conferência que abordou os impactos humanitários das armas nucleares, em Oslo, Noruega, com a participação de 128 Estados e, também, de representantes de diversas organizações da sociedade civil, contando com a autoexclusão dos países nucleares (P5). A conferência trouxe a abordagem humanitária ao centro do debate internacional, concentrando as exposições nos fatos provenientes de uma detonação nuclear, incluindo suas características e seu impacto nos seres humanos e no meio ambiente. (LEWIS e WILLIAM, 2013, p.80)

As conclusões da conferência enfatizaram que as vítimas e os estragos imediatos de uma explosão nuclear são tão amplos que seria praticamente impossível prestar qualquer assistência adequada. A Conferência de Oslo representou uma mudança no discurso internacional sobre armas nucleares que até então era tratado em termos políticos e de estratégia militar. Este movimento continuou em uma nova discussão em 2014, durante conferência que também se concentrou sobre os impactos humanitários das armas nucleares, realizada na cidade de Nayarit, México, com a participação de representantes de mais de 140 Estados. (LEWIS e WILLIAM, 2013, p.87)

Já em 2015 foi realizada a nona Conferência de Revisão do TNP, em Nova Iorque. Entretanto, nessa ocasião, diferenças entre os Estados participantes, principalmente em relação às políticas para o Oriente Médio, impediram a conclusão satisfatória de um acordo que visaria transformar aquela região em mais uma zona livre de armas nucleares. Na referida conferência, a abordagem humanitária às armas nucleares ganhou mais uma vez espaço através da discussão da possibilidade da construção de um tratado para banir as armas nucleares, contando com o apoio de mais de 100 Estados, entretanto, sem apoio de nenhum dos “Estados nucleares". (RADIO ONU, 2016) 
Existe uma série de pressupostos intrinsecamente contraditórios aos princípios e normas do Direito Internacional Humanitário, tais como o sofrimento desnecessário evidente que poderia ser causado ante uma detonação, a impossibilidade de distinção entre alvos civis e militares e a completa imprecisão e desproporcionalidade quanto ao alcance e poder de destruição destas armas.

Sob a perspectiva do Direito Internacional Humanitário, é bastante óbvio que a posse, uso e armazenamento de armas nucleares violam seus princípios. A legalidade da posse de armas nucleares frequentemente não é separada dos interesses políticos que envolvem esta questão. Enquanto os Estados que não possuem armas nucleares reiteram a ilegalidade de seu uso, os Estados que possuem armas nucleares resistem a qualquer tentativa explícita para seu banimento. Portanto, não há qualquer convenção internacional proibindo armas nucleares. (THÜRER, 2008, p.94).

Em que pese a previsão do artigo VI do TNP prever o compromisso das partes em entabular, de boa fé, um tratado de desarmamento geral, efetivo e completo, muito pouco tem se demonstrado o esforço dos "Estados nucleares" em efetivamente caminhar nesta direção. 0 próprio tratado de não proliferação de armas nucleares é uma fonte que garante a legitimidade da posse de armamento nuclear por parte destes países. Por isso, a necessidade da construção de um novo tratado com foco no efetivo desarmamento nuclear. Neste sentido o esforço da abordagem humanitária, por parte da sociedade civil organizada e organizações não governamentais, soma-se à voz dos "Estados não nucleares" no pleito de um novo tratado. (RITCHIE, 2013, p. 47).

A experiência angariada, por exemplo, com os processos de Ottawa e Oslo demonstraram que a estigmatização internacional da posse e uso de minas terrestres e munições clusters foi essencial que ocorresse sua deslegitimação enquanto meio de guerra aceitável, tornando o uso destas armas jurídica e moralmente inaceitáveis, abrindo o caminho para seu banimento completo. Neste sentido, o esforço da perspectiva humanitária aplicado à questão nuclear também tem a pretensão de estabelecer um novo nível de aceitabilidade moral pelos atores do cenário internacional sobre a posse das armas nucleares. (RITCHIE, 2013, p. 52) 
Entretanto, deve-se ter em conta que o approach humanitário às armas nucleares se trata de um desafio novo, maior e totalmente diferente dos processos anteriormente mencionados. Isso ocorre, tendo em vista as características únicas do armamento nuclear, o papel diferenciado que a simples posse destas armas desempenha do ponto de vista da dissuasão no cenário internacional, a valorização da doutrina militar da destruição mútua assegurada (mutual assured destruction), as características e alianças geopolíticas específicas dos grupos de países nucleares e outros (BORRIE, 2013, p.33) e seu dilema com relação ao papel da OTAN, bem explicitado na votação da resolução L.41 do $1^{\text {a }}$ Comitê da AGNU.

Ante ao exposto, observa-se que a abordagem humanitária à questão nuclear tem gerado importante veio de atuação diplomática, realizada com atuação de atores da sociedade civil em fóruns multilaterais. O objetivo tem sido buscar a deslegitimação e consequente proibição e banimento deste tipo de armamento, através do estabelecimento de um novo eixo de debates e negociações em torno da temática, tendo em vista que há uma considerável frustração por meio dos "Estados não nucleares" no que tange aos avanços efetivos de seus esforços em fóruns tradicionais, que até então eram dominados pelas potências nucleares.

\section{CONSIDERAÇÕES FINAIS}

A contenção da ameaça nuclear é e seguirá sendo um dos desafios relevantes para a construção da paz. E mesmo que houvesse a erradicação total das armas nucleares existentes, elas não poderiam mais ser desinventadas, ou seja, sempre poderá haver ameaça futura entorno da questão nuclear. Razão pela qual todos os caminhos para a paz também são mecanismos de contenção destes graves instrumentos de morte e destruição - nisso inclui-se a sinergia necessária entre a educação para a paz e a educação para o desarmamento, o papel do desarmamento nos processos de construção da paz e o desarmamento de per si.

Infelizmente, as últimas conferências de revisão/exame do TNP não alcançaram êxitos satisfatórios para realização do efetivo desarmamento nuclear, negociado em boafé pelos países nucleares. Ao invés de diminuir a lista dos detentores de armas nucleares, 
Índia, Paquistão e Coreia do Norte foram incorporados à condição de potências nucleares. Sem falar das controvérsias quanto ao programa nuclear iraniano.

De outro lado, os mecanismos de construção de paz, ligados à construção de confiança mútua, como verificação e cooperação técnica, que permitam reconstrução de credibilidade entre os atores internacionais, são passos imprescindíveis para os processos de controle de armas e desarmamento e para encaminhar os conflitos existentes aos mecanismos de solução pacífica de controvérsias internacionais. Caminhos do desarmamento humanitário demonstram possibilidades que devem ser valorizadas, como erradicação de minas terrestres antipessoal e munições cluster e experiências acerca das quais há muito o que aprender.

Inexiste um demarcador claro de orientação política que diferencie a ação enquanto estratégico-militar e/ou humanitária. Os discursos diplomáticos rotineiramente encobrem as reais motivações dos posicionamentos dos Estados. Ao mesmo tempo, a forma de construção dos discursos diplomáticos ao longo dos últimos quarenta anos demonstra a necessidade cada vez maior de pautar as consequências humanitárias de seus atos e decisões, ante a pressão da opinião pública nacional e internacional.

Além disso, percebe-se uma possível conjugação entre paz, estratégia militar e desafios humanitários quando evoca-se o caminho percorrido por Argentina e Brasil. Uma opção pelo desarmamento como estratégia militar contribuiu de modo importante para selar a paz entre os países fronteiriços, criando opção de ampliar a integração e permitindo, assim, prevenção de graves consequências ambientais e humanitárias.

Por isso, percebe-se que os caminhos para a paz o são para a proibição das armas nucleares e vice-versa. A sinergia entre ambos faz com que o condicionamento recíproco entre um e outro, pavimentando velhos e novos caminhos para a paz - como o caso da campanha pela proibição das armas nucleares por força dos seus impactos humanitários. A nova abordagem trará novos caminhos para o enfrentamento, mas também novos desafios.

Nesse sentido, para que estes processos tenham efeito e mobilizem a vontade política internacional, é fundamental o fomento e a abertura para atuação ampla e 
participativa da sociedade civil, mobilização da opinião pública, como o Processo de Ottawa pela erradicação das minas terrestres já demonstrou, entre outros. Ou seja, sociedade civil e opinião pública podem desempenhar um papel-chave na construção da vontade política pela proibição das armas nucleares, mas, para isso, é preciso que os processos de negociação sejam mais abertos e transparentes do que a diplomacia tradicional tem demonstrado.

\section{REFERÊNCIAS BIBLIOGRÁFICAS}

BORRIE, John; CAUGHLEY, Tim. Viewing Nuclear Weapons through a Humanitarian Lens. Genebra: UNIDIR, 2013.

BORRIE, John. Viewing nuclear weapons through a humanitarian lens: context and implications. In: BORRIE, John; CAUGHLEY, Tim. Viewing Nuclear Weapong through a Humanitarian Lens. Genebra: UNDIR, 2013, Cap.2, p. 29-43.

CAUGHLEY, Tim. Tracing notions about humanitarian consequences. In: BORRIE, John; CAUGHLEY, Tim. Viewing Nuclear Weapons through a Humanitarian Lens. Genebra: UNIDIR, 2013, Cap.1, p. 14-28.

CORTRIGHT, David. Peace: a history of movements and ideas. Cambridge: Cambridge University, 2009.

DHESARME - Ação pelo Desarmamento Humanitário. Proibição de Armas Nucleares é aprovada por 123 Estados. <http://www.dhesarme.org/proibicao-de-armasnucleares-e-aprovada-por-123-paises-resolucao-da-onu-pela-negociacao-em2017/>. Disponível em 31 out. 2016.

GREENPEACE. The History of Greenpeace. Disponível em: $<$ http://www.greenpeace.org/australia/en/about/history/ >. Acesso em: 30 setembro 2016.

HERZ, Monica; LAGE, Victor Coutinho. A Atual Política Nuclear Brasileira. Policy Brief. BRICS Policy Center. Rio de Janeiro: PUC-Rio, Julho 2013.

ICANW. UN votes to outlaw nuclear weapons in 2017. Disponível em: <http://www.icanw.org/campaign-news/un-votes-to-outlaw-nuclear-weapons-in2017>. Acesso em: 01 novembro 2016.

ICJ- INTERNATIONAL COURT OF JUSTICE. Obligations concerning Negotiations relating to Cessation of the Nuclear Arms Race and to Nuclear Disarmament (Marshall Islands v. United Kingdom). Disponível em: <http://www.icjcij.org/docket/index.php?p1=3\&p2=3\&case=160>. Acesso em: 02 de novembro 2016.

LEWIS, Patricia; WILLIAMS, Heather. The meaning of the oslo conference on the humanitarian impacts of nuclear weapons. In: In: BORRIE, John; CAUGHLEY, Tim. 
Viewing Nuclear Weapons through a Humanitarian Lens. Genebra: UNIDIR, 2013, Cap.3, p. 78-94.

OLIVEIRA, Odete Maria de. Integração nuclear Brasil-Argentina: Uma estratégia compartilhada. Florianópolis: UFSC/Obra Jurídica, 1996.

OLIVEIRA, Odete Maria de. Os (Des)Caminhos do Brasil Nuclear. Ijuí: Unijuí, 1999.

SAMPAIO, Maria Feliciana Nunes Ortigão. O Tratado de Proibição Completa de Testes Nucleares (CTBT): Perspectivas para sua entrada em vigor e para a atuação diplomática brasileira. Brasília: Fundação Alexandre de Gusmão, 2012.

SILVA, Gabriel Francisco. O Brasil frente os Regimes de Desarmamento Humanitário: um estudo do caso de munições cluster (2008). Dissertação de Mestrado do Programa de Pós-Graduação em Relações Internacionais da UNB. Brasília, 2015.

SIPRI. SIPRI Yearbook 2014. Estocolmo: Oxford, 2015.

SIPRI. Nuclear Arms Control and Non-Proliferation. Disponível em: https://www.sipri.org/yearbook/2010/09. Acesso em: 02 de novembro 2016.

ONU. Carta das Nações Unidas, 1945.

RADIO ONU. Brasil lamenta falta de consenso sobre não-proliferação nuclear. Disponível em: http://www.unmultimedia.org/radio/portuguese/2015/06/brasil-lamentafalta-de-consenso-sobre-nao-proliferacao-nuclear/\#.WGz38n3z9dY. Acessado em 29 set, 2016.

REACHING CRITICAL WILL. Fissile Material Cut-Off Treaty. Disponível em: <http://www.reachingcriticalwill.org/resources/fact-sheets/critical-issues/4737fissile-material-cut-off-treaty>. Acessado em 01 nov. 2016.

RITCHIE, Nick. Legitmizing and delegitimizing nuclear weapons. In: BORRIE, John; CAUGHLEY, Tim. Viewing Nuclear Weapons through a Humanitarian Lens. Genebra: UNIDIR, 2013, Cap.3, p. 44-78.

THÜRER, Daniel. International Humanitarian Law: Theory, Practice, Context. Haia: The Hague Academy of International Law, 2008.

TRINDADE, Antonio Augusto Cançado. International Law for Humankind: toward a new jus gentium. Haia: The Hague Academy of International Law, 2005.

VIEIRA, Gustavo Oliveira. Inovações em Direito Internacional: um estudo de caso a partir do Tratado de Ottawa. Santa Cruz do Sul: Edunisc, 2006.

VIEIRA, Gustavo Oliveira; SITO, Santiago (Orgs.). O Tratado Banindo as Bombas Cluster e a Posição Brasileira: para qualificar o debate nacional. 2.ed. Santa Maria: Unifra, 2010. 